\title{
Análise das Propriedades Mecânicas de Juntas de Aço Carbono Estrutural Soldadas pelo Processo Arco Submerso com os Arcos Simples e Duplo (Tandem-Arc)
}

\author{
Marcello Ferrari ${ }^{1}$ (D) , Mauricio David Martins das Neves ${ }^{1}$ (D) , Juliano Neves Panão ${ }^{2}$ (D) \\ ${ }^{1}$ Instituto de Pesquisas Energéticas e Nucleares - IPEN, Centro de Ciência e Tecnologia de Materiais - CCTM, São Paulo, SP, Brasil. \\ ${ }^{2}$ Centro Estadual de Educação Tecnológica Paula Souza - FATEC, São Paulo, SP, Brasil.
}

Como citar: Ferrari M, Neves MDM, Panão JN. Análise das propriedades mecânicas de juntas de aço carbono estrutural soldadas pelo processo arco submerso com os arcos simples e duplo (Tandem-Arc). Soldagem \& Inspeção. 2019;24:e2402. https://doi.org/10.1590/0104-9224/SI2304.07

Resumo: Diante de um cenário econômico onde a concorrência é cada vez mais acirrada, a busca por processos, técnicas e equipamentos de soldagem que proporcionem ganhos na produtividade é uma exigência para garantir a competitividade das empresas no mercado. Com o desenvolvimento e a adoção de novas tecnologias é possível inovar os processos convencionais, otimizando o desempenho e aumentando a produtividade dos mesmos, sem detrimento dos requisitos de qualidade exigidos. O processo de soldagem arco submerso permite a obtenção de juntas soldadas de excelente qualidade e produtividade e, com a utilização de múltiplos arames, é possível aumentar ainda mais a taxa de deposição. Entretanto, o emprego de múltiplos arames implica na necessidade de maiores correntes e, mesmo com o aumento da velocidade de soldagem, o aporte de calor sofre um acréscimo considerável, o que pode afetar a tenacidade da junta. Assim, em estruturas soldadas onde há requisitos de impacto torna-se necessário avaliar os efeitos dos altos aportes de calor. Neste trabalho foi comparada a tenacidade de duas juntas soldadas em aço carbono ASTM A36 pelo processo arco submerso, sendo a primeira soldada com arco simples e a outra com arco duplo (Tandem-Arc). Após a soldagem, as peças de testes foram submetidas ao tratamento térmico de alívio de tensões (TTAT) e submetidas aos ensaios de tração, dobramento, impacto Charpy, perfil de dureza Vickers, exame macrográfico e caracterização microestrutural realizada por meio de microscopia óptica. Os resultados obtidos em todos os ensaios foram considerados satisfatórios e aprovados, mostrando assim que é possível o emprego do processo Tandem-Arc na soldagem de aços carbono quando há requisitos de impacto.

Palavras-chave: Arco submerso; Tandem-Arc; Tenacidade; Impacto charpy.

\section{Mechanical Properties Assessment of Structural Carbon Steel Welded Joints by Means of Submerged Arc Welding Process with Single Arc and Double Arc (Tandem-Arc)}

\begin{abstract}
Faced with an economic scenario where competition is increasingly intense, the search for processes, techniques and welding equipment that provide gains in productivity is a requirement to ensure the competitiveness of companies in the market. With the development and adoption of new technologies it is possible to innovate the conventional processes, optimizing the performance and increasing their productivity, without detriment to the required quality requirements. The process of submerged arc welding allows the obtainment of welded joints of excellent quality and productivity and, with the use of multiple wires, it is possible to increase the deposition rate even further. However, the use of multiple wires implies the need for higher currents and, even with increasing welding speed, the heat input increases considerably, which can affect the tenacity of the joint. Thus, in welded structures where there are impact requirements it becomes necessary to evaluate the effects of high heat inputs. In this work the strength of two welded joints in ASTM A36 carbon steel was compared by the submerged arc process, the first being welded with single arc and the other with double arc (Tandem-Arc). After welding, the test pieces were submitted to tensile stress treatment (TTAT) and subjected to tensile tests, folding, Charpy impact, Vickers hardness profile, macrographic examination and microstructural characterization performed using optical microscopy. The results obtained in all tests were considered satisfactory and approved, thus showing that it is possible to use the Tandem-Arc process in the welding of carbon steels when there are impact requirements.
\end{abstract}

Key-words: Submerged arc welding; Tandem-Arc; Toughness; Charpy V-Notch test. 


\section{Introdução}

O processo de soldagem arco submerso (Submerged Arc Welding - SAW) é largamente empregado na fabricação de tubos, navios, perfis, vasos de pressão, caldeiras e outros tipos de equipamento pesados, pelo fato de ser possível a obtenção de altas taxa de deposição, combinando qualidade e produtividade. No processo SAW o eletrodo é alimentado continuamente através de um sistema de tracionamento adequado à aplicação e o fluxo, sob a forma de grânulos, é alimentado à região da solda produzindo uma cobertura do arco e da poça de fusão, daí o nome "arco submerso".

Atualmente, a participação deste processo na fabricação em geral corresponde a cerca de $10 \%$ do volume de metal de solda depositado por arco elétrico. O processo SAW permite um alto grau de automatização e, por meio da utilização de arcos múltiplos, é possível aumentar ainda mais a taxa de deposição, podendo esta atingir a valores próximos a $45 \mathrm{~kg} / \mathrm{h}$ [1]. Basicamente, a soldagem com arcos múltiplos é a técnica de soldagem onde dois ou mais eletrodos alimentam uma mesma poça de fusão, sendo que cada eletrodo forma um arco elétrico controlado separadamente por cabeçote e fonte de energia independente. Assim, cada eletrodo possui alimentador de arame e fonte de energia própria, permitindo parametrizações diferentes para cada arco elétrico.

Cabe aqui dizer que o emprego do processo de soldagem SAW com arcos múltiplos muitas vezes representa um aporte de calor maior que o gerado pelo processo com arco simples. Outro aspecto a ser considerado é que a menor quantidade de passes pode acarretar em redução da tenacidade da junta soldada devido à redução do efeito do revenimento na soldagem multi-passes.

Um alto aporte promove a formação de estruturas grosseiras que afetam de forma deletéria o comportamento da junta diante das solicitações mecânicas. Deste modo, o correto balanceamento do aporte de calor é fundamental para garantir propriedades mecânicas e de tenacidade aceitáveis para a junta soldada, especialmente para estruturas onde há requisitos de impacto.

Neste trabalho, foi empregado o aço estrutural ASTM A36 [2] nas peças de testes. De acordo com o código ASME IX [3], tal aço é classificado como $P$ Number 1, Group Number 1 (P1Gr.1). É importante salientar que, ainda de acordo com o este código, a qualificação de um procedimento de soldagem com requisitos de impacto empregando-se uma peça de testes cujo metal de base é P1Gr.1, conforme QW-422, permite a soldagem de qualquer outro material P1 Gr.1 com requisitos de impacto [3].

A norma ASTM A36 não especifica requisitos de impacto para este material, mas tais ensaios podem ser executados em caráter suplementar conforme previsto no item S5 da referida norma [2]. Algumas normas européias, adotam o requisito de impacto como mandatório para certos tipos de aço, como por exemplo, o EN 10025-2 S235JR [4], similar ao ASTM A36, onde o valor mínimo de energia absorvida é $27 \mathrm{~J} \mathrm{a}+20^{\circ} \mathrm{C}$ sendo este o valor adotado neste trabalho como critério de aceitação.

\section{Matérias e Métodos}

O metal de base (MB) empregado neste trabalho foi uma chapa de aço carbono, condição "como laminado", conforme ASTM A36, com espessura de $50 \mathrm{~mm}$. A composição química e as propriedades mecânicas da chapa de testes estão descritas na Tabela 1.

Tabela 1. Composição química e Propriedades Mecânicas da chapa de testes.

\begin{tabular}{|c|c|c|c|c|c|c|c|c|}
\hline \multirow{3}{*}{ Valores } & \multicolumn{5}{|c|}{ Elementos - Valores em \% } & \multicolumn{3}{|c|}{ Propriedades Mecânicas } \\
\hline & \multirow{2}{*}{ C } & \multirow{2}{*}{ Mn } & \multirow{2}{*}{$\mathbf{P}$} & \multirow{2}{*}{$\mathbf{S}$} & \multirow{2}{*}{ Si } & TR & LE & Along. \\
\hline & & & & & & [MPa] & [MPa] & [\%] \\
\hline \multirow{2}{*}{ ASTM A36 } & 0,26 & 0,80 & 0,030 & 0,030 & 0,15 & 400 & 250 & $20 \%$ \\
\hline & Máx. & 1,20 & máx. & máx. & 0,40 & 550 & mín. & mín. \\
\hline Certificado & 0,16 & 1,08 & 0,018 & 0,010 & 0,31 & 467 & 291 & 33 \\
\hline
\end{tabular}

Na soldagem das peças de testes foi empregado o arame sólido conforme a especificação AWS 5.17, classificado como EM12K, com diâmetro de 3,97 mm e fluxo aglomerado neutro [5]. A composição química do arame está listada na Tabela 2.

Tabela 2. Composição química, valor em [\%] - Arame sólido EM12K.

\begin{tabular}{ccccccc}
\hline Elementos & $\mathbf{C}$ & $\mathbf{M n}$ & $\mathbf{P}$ & $\mathbf{S}$ & $\mathbf{S i}$ \\
EM12K & 0,05 & 0,80 & 0,030 & 0,030 & 0,10 \\
Certificado & 0,15 & 1,25 & máx. & máx. & 0,35 \\
\hline
\end{tabular}

As peças de testes foram preparadas pelo processo oxicorte, na qual quatro chapas de $50 \mathrm{~mm}$ de espessura foram cortadas nas dimensões $200 \times 1000 \mathrm{~mm}$ de modo a permitir a montagem de duas peças de testes, a saber: PT-01, para a soldagem com arco simples e PT-02, para a soldagem com arco duplo (Tandem Arc). As chapas foram cortadas de modo que a 
solda executada ficasse posicionada na direção transversal ao sentido de laminação da chapa. Para cada peça de testes, uma chapa foi biselada em " $\mathrm{K}$ ' com ângulo de $45^{\circ}$ e a outra mantida com a face reta de modo a formar um chanfro em " $\mathrm{K}$ " com abertura de raiz de $3 \mathrm{~mm}$ após a montagem. Após a montagem as peças de testes foram posicionadas e fixadas na posição plana (1G). A raiz de ambas as peças de testes foram soldadas pelo processo GMAW com o arame Metal-Cored E70T15. O sistema de soldagem utilizado para a soldagem dos passes de enchimento e acabamento pelo processo Arco Submerso (SAW) foi o mesmo: um equipamento Tandem-Arc com trator, com um arranjo do tipo CC-CA e espaçamento entre as tochas de $16 \mathrm{~mm}$ e um ângulo entre $10^{\circ}$ e $15^{\circ}$. Para a peça de teste PT-01 foi utilizada apenas a tocha CC, enquanto que para a soldagem da peça de testes PT-02 foi utilizada ambas as tochas, CC-CA. A Figura 1 mostra a visão geral do trator tandem do equipamento empregado nos testes e o detalhe das tochas.

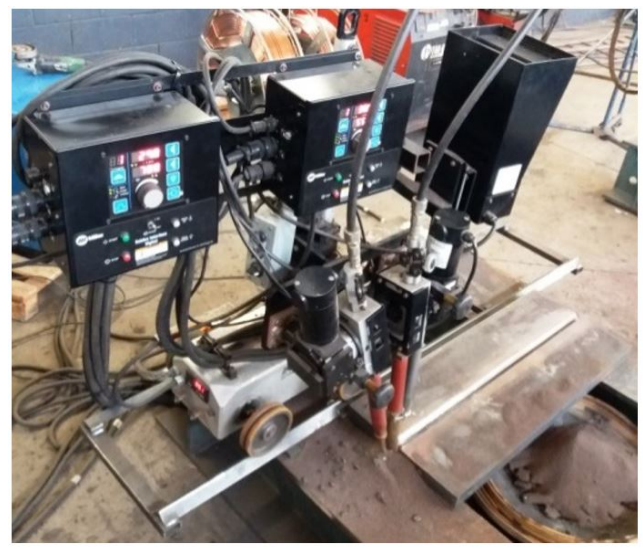

(a)

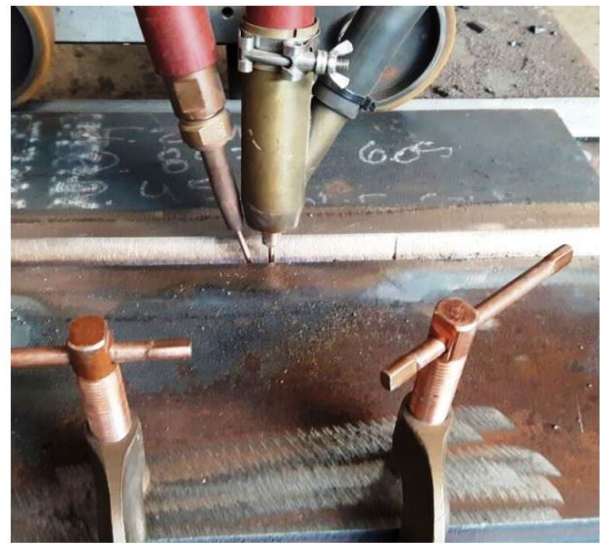

(b)

Figura 1. Arranjo do Equipamento SAW Tandem Arc. (a) Visão geral; (b) Detalhe das tochas em tandem.

Antes da soldagem as peças de testes foram pré-aquecidas por meio de chama até atingir uma temperatura de $75{ }^{\circ} \mathrm{C}$ e controlada por meio de pirômetro de contato. A temperatura máxima de interpasses foi de $250{ }^{\circ} \mathrm{C}[6]$.

A peça de testes PT-01 (arco simples) foi soldada com um arame e nela foram depositados 29 passes distribuídos em 15 camadas. A peça de teste PT-02 (arco duplo) foi soldada com 2 arames e nela foram depositados 12 passes distribuídos em 12 camadas. A faixa dos parâmetros de soldagem empregada nas peças de testes está descrita na Tabela 3.

Tabela 3. Faixa dos parâmetros de soldagem empregados nas peças de teste PT-01 e PT-02.

\begin{tabular}{cccc}
\hline Parâmetro & PT-01 & PT-02 & Slave \\
\cline { 2 - 3 } Corrente / Polaridade & CC+ & CC+ & CA \\
Corrente (I) & $547-659 \mathrm{~A}$ & $546-663 \mathrm{~A}$ & $558-686 \mathrm{~A}$ \\
Tensão (U) & $29-32 \mathrm{~V}$ & $29-33 \mathrm{~V}-31 \mathrm{~V}$ & $40-45$ \\
Stick-Out (mm) & $25-30$ & $25-30$ & $8,4-12,0 \mathrm{~mm} / \mathrm{s}$ \\
Velocidade de soldagem (v) & $5,9-9,7 \mathrm{~mm} / \mathrm{s}$ & $4,2 \mathrm{~kJ} / \mathrm{mm}$ \\
Aporte de calor máximo (HI máx.) & $2,8 \mathrm{~kJ} / \mathrm{mm}$ &
\end{tabular}

Após a soldagem, ambas as peças foram submetidas a um tratamento térmico de alívio de tensões (TTAT) na mesma carga do forno. A temperatura e o tempo de patamar foram, respectivamente, de $600{ }^{\circ} \mathrm{C}$ e 8,0 horas. A temperatura de início e final de controle foi de $425^{\circ} \mathrm{C}$ e as taxas máximas foram de $100^{\circ} \mathrm{C} / \mathrm{h}$ para o aquecimento e $140{ }^{\circ} \mathrm{C} / \mathrm{h}$ para o resfriamento [7]. A seguir, das peças de testes PT-01 e PT-02 foram removidos os corpos de prova para os ensaios mecânicos (tração de dobramento), de dureza e impacto Charpy. Também foram removidos corpos de prova para os exames macrográfico e de caracterização microestrutural. Os corpos de prova para os ensaios mecânicos foram preparados conforme norma ASTM A370 [8]. O perfil de medição de durezas HV5 foi baseado na norma Petrobras N-133 [6]. O ensaio de impacto Charpy foi realizado com base nas considerações da norma ASME VIII Div.1 [7] sendo os corpos de prova removidos do metal de solda a $1,5 \mathrm{~mm}$ da superfície e entre $1 / 4$ e $1 / 2$ da superfície do lado oposto. Na zona afetada pelo calor (ZAC) os corpos de prova foram removidos entre $1 / 4$ e $1 / 2$ da superfície de um lado e do lado oposto. De cada região foi removido um "set" constituído por três corpos de prova. Os corpos de prova foram ensaiados nas temperaturas de $-20^{\circ} \mathrm{C}, 0^{\circ} \mathrm{Ce}+20^{\circ} \mathrm{C}$. A Figura 2 mostra os locais de medição de dureza e de remoção dos corpos de prova para ensaio de impacto Charpy. 


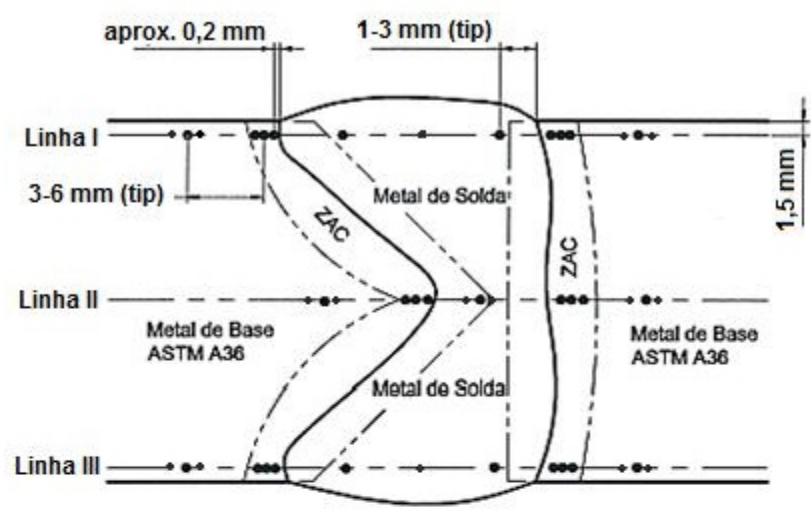

(a)

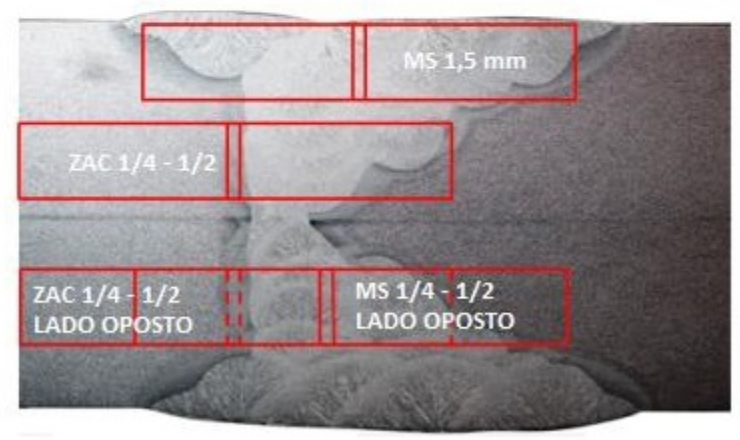

(b)

Figura 2. (a) Locais de medição de dureza. (b) Locais de remoção dos corpos de prova ensaio de impacto Charpy.

\section{Resultados e Discussão}

Para cada uma das peças foram extraídos dois corpos de prova de tração reduzidos conforme requerido pelo ASME IX. Para a peça de testes PT-01 (arco simples) o valor médio dos dois ensaios para o limite de resistência (LR) foi de $479 \mathrm{MPa}$ enquanto que para a peça de testes PT-02 (arco duplo) tal valor médio foi de $486 \mathrm{MPa}$. Apenas o valor de LR foi medido neste trabalho, embora fosse possível também a medição do limite de escoamento, alongamento e redução de área, sendo estes dois últimos apenas a título informativo, pois a existência de diversas regiões (metal de solda, zona afetada pelo calor e metal de base) com propriedades mecânicas distintas tornam tais medidas poucos confiáveis e com baixa acuracidade [9].

A ruptura de todos os corpos de prova ocorreu no metal de base, o que era de se esperar visto que o metal de solda em geral contém uma alta densidade de discordâncias que também contribui para aumentar os limites de resistência nos aços carbono. O resultado final é que o metal de solda possui maiores limites de resistência do que o metal de base, mesmo quanto o conteúdo de carbono e/ou elementos de liga é inferior [10].

O critério de aceitação, conforme o item QW-153 do ASME IX, diz que o corpo de prova deve apresentar um limite de resistência maior que o mínimo especificado para o metal de base, que é de $400 \mathrm{MPa}$ para o ASTM A36. Deste modo, pela análise dos resultados obtidos, pode-se concluir que o ensaio foi aprovado para a soldagem com arco simples e com arco duplo.

Os quatro corpos de prova da PT-01 e os quatro da PT-02 submetidos ao ensaio de dobramento lateral não mostraram quaisquer descontinuidades na região de interface entre MB, ZAC e MS após o ensaio. Os resultados obtidos nos ensaios evidenciaram que houve perfeita fusão e boa ductilidade sendo, portanto aprovados com base na inspeção visual da junta soldada.

A Figura 3 mostra o aspecto da macrografia da junta em "K" da PT-01 e PT-02. Em ambos os corpos de prova o exame macrográfico revelou uma solda isenta de porosidades, inclusões de escória, falta de fusão e trincas. Nota-se a presença de maior quantidade de passes na macrografia da PT-01 se comparada à macrografia da PT-02. Também é evidente a presença de regiões colunares onde a maior porcentagem encontra-se na região do reforço da solda. Também nota-se a presença de regiões de grãos grosseiros e refinados. 


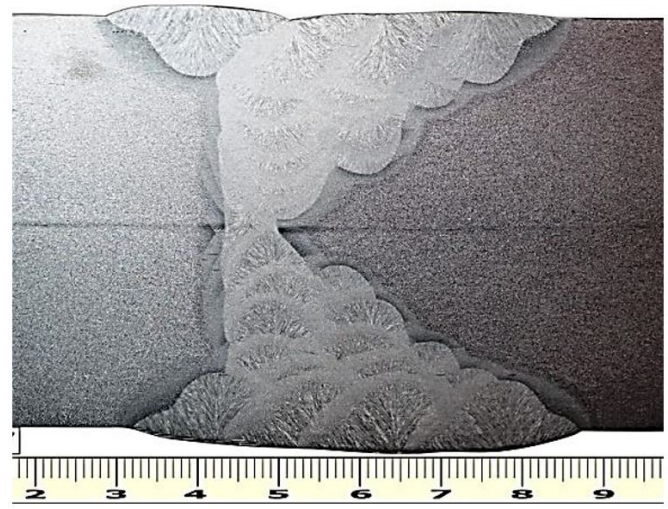

(a)

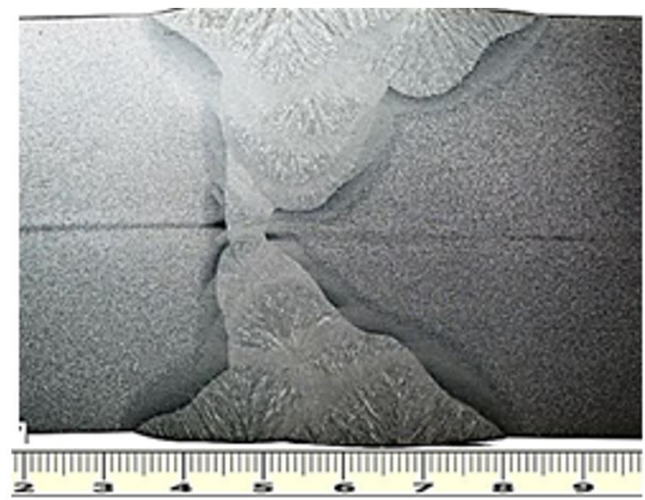

(b)

Figura 3. Macrografias (a) Peça de testes PT-01 (arco simples). (b) Peça de teste PT-02 (arco duplo). Ataque: Nital 5\%.

Em ambas as macrografias foram possíveis observar as linhas de segregação, no centro da chapa, fenômeno típico na laminação de chapas grossas. Nas zonas afetadas pelo calor - ZAC's é possível notar uma variação progressiva da coloração onde se pode distinguir a região onde a temperatura excede a temperatura $\mathrm{A} 1$ e a região totalmente austenitizada pelo aquecimento acima da linha $A 3$ [11].

A dureza na região da zona afetada pelo calor (ZAC) pode ser prevista por alguns modelos onde o de Yurioka et al. [12] assume uma posição de destaque. Este modelo leva em consideração fatores como o tempo de resfriamento da junta entre $800{ }^{\circ} \mathrm{C}$ e $500^{\circ} \mathrm{C}$ (t/8/5) e a composição química do metal de base conforme as equações de 1 a $5:$

$\mathrm{Hv}=\frac{\mathrm{Hm}+\mathrm{Hb}}{2}-\frac{\mathrm{Hm}-\mathrm{Hb}}{2,2} \cdot \arctan \left[\left(\frac{4 \cdot \log (\mathrm{t} 8 / 5 / \mathrm{tm})}{\log (\mathrm{tb} / \mathrm{tm})}\right)-2\right]$

Onde:

$$
\begin{aligned}
& \mathrm{Hm}=884 \cdot \mathrm{C}\left(1-0,3 \mathrm{C}^{2}\right)+294 \\
& \mathrm{tm}=\exp \left(10.6 \cdot \mathrm{CE}_{\mathrm{I}}-4,8\right), \text { onde: } \mathrm{CE}_{\mathrm{I}}=\mathrm{C}+\mathrm{Si} / 24+\mathrm{Mn} / 6 \\
& \mathrm{Hb}=145+130 \tanh \left(2,65 \cdot \mathrm{CE}_{\mathrm{II}}-0,69\right), \text { onde: } \mathrm{CE}_{\mathrm{II}}=\mathrm{C}+\mathrm{Si} / 24+\mathrm{Mn} / 5 \\
& \mathrm{tb}=\exp \left(6,2 \mathrm{CE}_{\mathrm{III}}+0,74\right), \text { onde: } \mathrm{CE}_{\mathrm{III}}=\mathrm{C}+\mathrm{Mn} / 3,6
\end{aligned}
$$

O tempo de resfriamento t8/5 foi calculado com base na norma DIN EN 1011-2 [13], obtendo-se um valor médio de 20s para a PT-01 e 35s para a PT-02. Com base nas equações de Yurioka para a previsão da dureza máxima nas ZAC's das peças de testes deste trabalho foram estimadas a dureza 198 HV5 para a PT-01 e a dureza de 186 HV5 para a PT-02. Tais resultados eram esperados, visto que, de acordo com Equação 1, um aumento no tempo de resfriamento t8/5, mantendo-se as outras variáveis constantes, implica em uma redução na dureza. Ao lado das estimativas de durezas nas ZAC's, também foram realizadas medições reais de dureza não apenas nessa região, mas também no metal de base e metal de solda. As macrografias das peças de testes PT-01 e PT-02 foram aproveitadas para a realização dos ensaios de dureza Vickers HV-5 conforme perfil mostrado na Figura 2. A média dos valores obtidos com seus respectivos desvios padrão foram plotados em um gráfico conforme mostrado na Figura 4. 


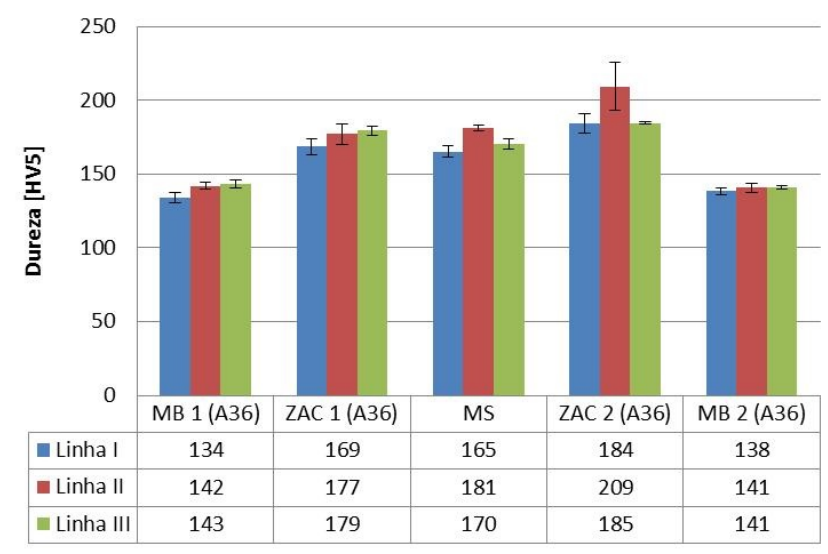

(a)

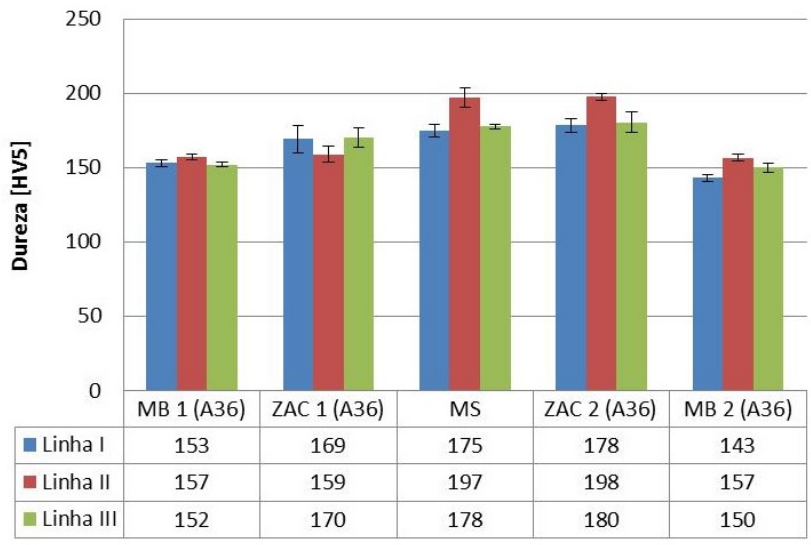

(b)

Figura 4. Gráfico comparativo dos perfis de dureza - (a) PT-01 (arco simples) e (b) PT-02 (arco duplo). Valores médios em HV5.

A análise dos gráficos mostra que na região do metal de base (MB), ocorreu um aumento de dureza na PT-02 comparado à PT-01. Tal incremento vem de encontro com os resultados dos ensaios de tração, onde as tensões de ruptura dos corpos de prova da PT-02 foram ligeiramente superiores as das PT-01. Esse aumento de dureza pode ser explicado pelo maior aporte de calor na soldagem com arco duplo (PT-02), onde as maiores expansões térmicas induzem maiores tensões residuais no metal de base [14].

De qualquer modo os valores de dureza medidos no MB para ambas as peças de testes eram os esperados para o ASTM A36, cujos valores para a condição "como laminado" estão na faixa de 130 - 150 HB [15].

$\mathrm{Na}$ ZAC, foi observado maiores valores de dureza, o que era esperado em virtude da formação de outros microconstituintes além da ferrita e perlita, como a bainita ou mesmo a martensita, durante as transformações no estado sólido ocorridas no resfriamento da junta. Notam-se também valores de durezas menores nas ZAC's da PT-02 comparados aos medidos na PT-01.

Tais resultados eram esperados, visto que, de acordo com Equação 1, um aumento no tempo de resfriamento t8/5, mantendo-se as outras variáveis constantes, implica em uma redução na dureza. O que chama um pouco a atenção é o fato de, apesar de ambos os lados da junta serem de ASTM A36, um dos lados apresenta maiores valores de dureza na ZAC, especialmente na linha II, próxima a raiz da solda. Tal fato pode ser explicado pela geometria da junta: no lado em "K", há a tendência de maior diluição entre o metal de adição e metal de solda comparado à diluição ocorrida no lado plano.

Finalmente, no metal de solda, como era esperado, os valores de dureza também foram relativamente altos comparados ao metal de base, principalmente na região da raiz. De fato, a diluição nessa região é mais pronunciada, o que favorece um aumento do teor de carbono e elementos de liga na composição do metal de solda. Também devem ser considerados os efeitos das tensões residuais, onde a expansão térmica do metal de solda é bastante limitada devido à ação do metal de base mais frio ficando assim sobre compressão após a solidificação.

No que tange a tenacidade das juntas a Tabela 4 mostra os valores obtidos no ensaio de impacto $\mathrm{Charpy}$ à $-20^{\circ} \mathrm{C}, 0{ }^{\circ} \mathrm{C} \mathrm{e}$ $20^{\circ} \mathrm{C}$ após o TTAT. A Figura 5 mostra um gráfico comparativo dos valores médios de energia absorvida pelos corpos de prova removidos das peças de testes PT-01 e PT-02 após TTAT. 


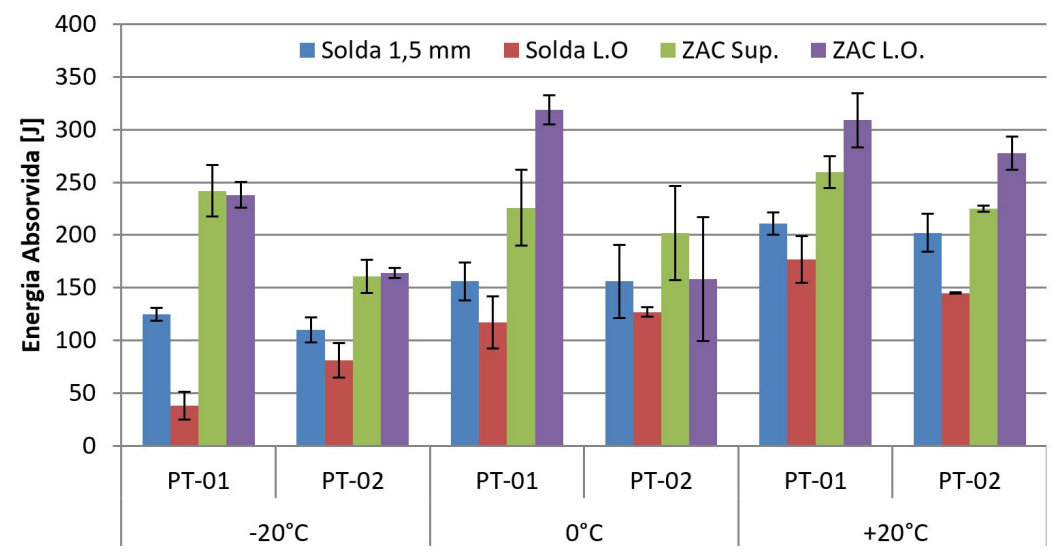

Figura 5. Gráfico comparativo dos valores de energia absorvida, ensaio de impacto Charpy PT-01 e PT-02.

Tabela 4. Valores obtidos nos ensaio de impacto Charpy.

\begin{tabular}{|c|c|c|c|c|c|c|c|c|c|c|c|c|}
\hline \multirow{3}{*}{ Região do Entalhe } & \multicolumn{6}{|c|}{ PT-01 (arco simples) } & \multicolumn{6}{|c|}{ PT-02 (arco duplo) } \\
\hline & \multicolumn{3}{|c|}{ Energia absorvida [J] } & \multicolumn{3}{|c|}{$\overline{\boldsymbol{x}} \pm \sigma[\mathbf{J}]$} & \multicolumn{3}{|c|}{ Energia absorvida [J] } & \multicolumn{3}{|c|}{$\overline{\boldsymbol{x}} \pm \sigma[\mathbf{J}]$} \\
\hline & $-20^{\circ} \mathrm{C}$ & $0^{\circ} \mathrm{C}$ & $+20^{\circ} \mathrm{C}$ & $-20^{\circ} \mathrm{C}$ & $0^{\circ} \mathrm{C}$ & $+20^{\circ} \mathrm{C}$ & $-20^{\circ} \mathrm{C}$ & $0^{\circ} \mathrm{C}$ & $+20^{\circ} \mathrm{C}$ & $-20^{\circ} \mathrm{C}$ & $0^{\circ} \mathrm{C}$ & $+20^{\circ} \mathrm{C}$ \\
\hline \multirow{3}{*}{ Solda $1,5 \mathrm{~mm}$ sup. } & 130 & 145 & 202 & & & & 123 & 142 & 195 & & & \\
\hline & 118 & 147 & 223 & $125 \pm 6$ & $156 \pm 18$ & $211 \pm 11$ & 99 & 131 & 222 & $110 \pm 12$ & $156 \pm 35$ & $202 \pm 18$ \\
\hline & 126 & 177 & 209 & & & & 108 & 196 & 188 & & & \\
\hline \multirow{3}{*}{ Solda $1 / 4$ e $1 / 2$ lado oposto } & 25 & 107 & 151 & & & & 62 & 124 & 145 & & & \\
\hline & 39 & 99 & 188 & $38 \pm 13$ & $117 \pm 25$ & $177 \pm 22$ & 93 & 132 & 145 & $81 \pm 17$ & $127 \pm 5$ & $145 \pm 1$ \\
\hline & 51 & 145 & 191 & & & & 88 & 124 & 146 & & & \\
\hline \multirow{3}{*}{ ZAC $1 / 4$ e $1 / 2$ superior } & 266 & 246 & 272 & & & & 147 & 198 & 228 & & & \\
\hline & 217 & 185 & 243 & $242 \pm 25$ & $226 \pm 36$ & $260 \pm 15$ & 178 & 159 & 224 & $161 \pm 16$ & $202 \pm 45$ & $225 \pm 3$ \\
\hline & 244 & 248 & 265 & & & & 158 & 248 & 222 & & & \\
\hline \multirow{3}{*}{ ZAC $1 / 4$ e $1 / 2$ lado oposto } & 251 & 334 & 282 & & & & 166 & 201 & 281 & & & \\
\hline & 227 & 314 & 311 & $238 \pm 12$ & $319 \pm 14$ & $309 \pm 26$ & 167 & 182 & 292 & $164 \pm 5$ & $158 \pm 59$ & $278 \pm 16$ \\
\hline & 235 & 308 & 333 & & & & 158 & 91 & 261 & & & \\
\hline
\end{tabular}

A respeito dos valores de tenacidade encontrados cabem aqui algumas considerações preliminares. O posicionamento do entalhe do corpo de prova na ZAC mostra-se problemático, visto que, na região da linha de fusão existe uma grande variedade de microestruturas que abrange o metal de solda e o metal de base. Por esse motivo, as juntas soldadas das peças de testes deste trabalho são em formato "K", onde o entalhe dos corpos de prova Charpy foi posicionado no lado reto da junta.

Pela análise da tabela e do gráfico, nota-se que os maiores valores de tenacidade foram obtidos na ZAC's de ambas as peças de testes, PT-01 e PT-02. Por outro lado, os menores valores foram encontrados no metal de solda. Considerando-se a composição química do metal de solda depositado conforme a Tabela 2 e os parâmetros de soldagem empregados, uma microestrutura composta basicamente por ferrita era esperada.

Aqui cabe destacar quais são os fatores que controlam as propriedades do metal de solda, mais especificamente a tenacidade, que segundo Evans e Bailey [16] são:

(i) Taxa de resfriamento;

(ii) Número de passes e como cada passe modifica a microestrutura do anterior;

(iii) Composição química do metal de solda.

O tempo de resfriamento (t8/5) é controlado pelo aporte de calor, temperatura de pré-aquecimento e interpasses. Taxas de resfriamento mais baixas produzem microestruturas mais grosseiras o que tendem a reduzir a tenacidade [16]. Cabe aqui salientar que os corpos de prova de impacto Charpy para avaliação do metal de solda foram removidos próximos a face da solda e na raiz da junta, onde as taxas de transferência de calor são distintas. O número e a sequência de passes são importantes nas soldas de aços ferríticos, pois cada passe aquece uma porção do metal de solda pré-existente acima da temperatura de transformação formando austenita. Aquecendo a altas temperaturas, os grãos de austenita crescem e no resfriamento há a formação de microestruturas grosseiras, enquanto o aquecimento a temperaturas mais baixas resultam 
em microestruturas mais finas o que apresenta melhor tenacidade $[10,11,16]$. Na soldagem com arco duplo o número de passes é menor e assim menor, em tese, seria a fração de metal de solda refinado pelos passes subsequentes. Era de se esperar portanto menores valores de tenacidade se comparados aqueles obtidos com arco simples, porém os resultados mostram que os valores encontrados são muito próximos para ambas as condições. É possível que o maior aporte de calor no processo com arco duplo tenha sido de algum modo benéfico para o metal de solda no sentido de favorecer o efeito de revenimento entre passes. Entretanto, nota-se a presença de uma série de baixos valores no metal de solda da PT-01 ensaiada a $-20{ }^{\circ} \mathrm{C}$ (média de $38 \mathrm{~J}$ ). Cabe aqui salientar que a posição do entalhe em relação a região colunar afeta de modo siginificativo o resultado do ensaio: se posicionado de forma paralela a região colunar, os valores obtidos serão baixos. Também deve ser considerado o efeito de diluição na região da raiz da solda. Como os teores de carbono nos metais de base são superiores aos do metal de adição, é de se esperar um teor de carbono na região da raiz maior que no enchimento. Cabe lembrar que a temperatura de transição é aumentada em torno de $14{ }^{\circ} \mathrm{C}$ para cada acréscimo de $0,1 \%$ no teor de carbono [17]. De fato, os valores de tenacidade encontrados próximos a raiz foram os menores da junta soldada. A queda da tenacidade no metal de solda também é decorrente da alteração de morfologia da ferrita, precipitação e coalescimento de carbonetos de ferro (FeC - cementita) após o TTAT.

De qualquer modo, os resultados obtidos foram bastante satisfatórios, considerando um valor mínimo aceitável de 27J, mesmo a $-20^{\circ} \mathrm{C}$, o que sugere que a temperatura de transição dúctil-frágil seja ainda menor que esta. De fato, baseado em alguns modelos de previsão da tenacidade da solda baseados em redes neurais artificiais, para a composição química do metal de solda deste trabalho, é estimado uma temperatura de transição média de $-60{ }^{\circ} \mathrm{C} \pm 25^{\circ} \mathrm{C}$, para $27 \mathrm{~J}$ [18].

Levando-se em consideração uma taxa de resfriamento de $20 \mathrm{~K} / \mathrm{s}$ os diagramas TTT e CCT do ASTM A36 indicam a formação de uma microestrutura composta basicamente por ferrita, perlita e possivelmente bainita e martensita nas regiões próximas à linha de fusão conforme ilustrado na Figura 6.

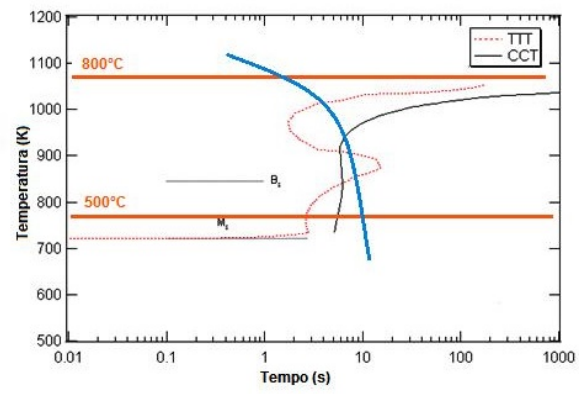

(a)

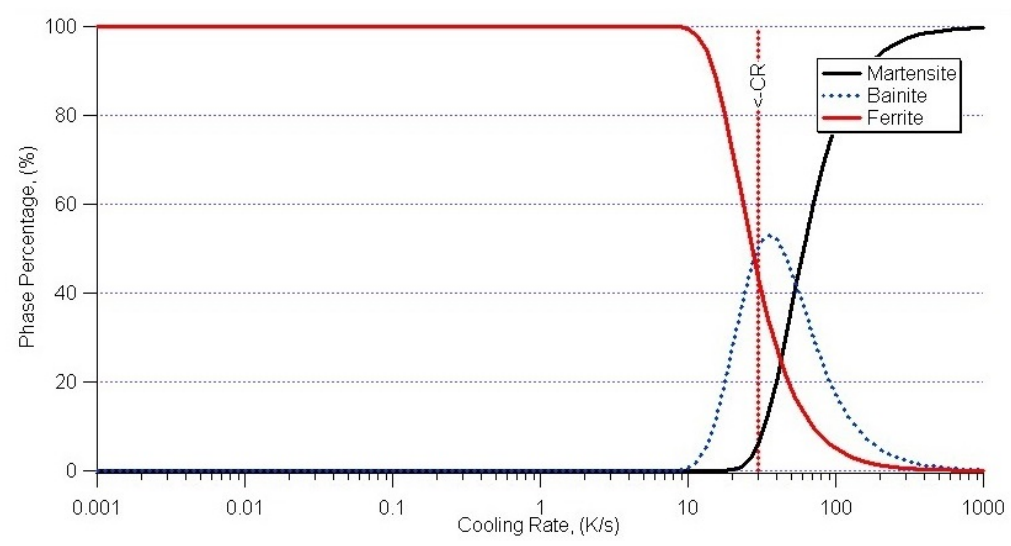

(b)

Figura 6. Diagramas (a e b) TTT e CCT para o aço ASTM A36, com previsão das frações volumétricas dos microconstituintes formados.

As Figuras 7 a 12 mostram o resultado do exame micrográfico realizado em corpos de prova removidos nas regiões da linha de fusão da solda de enchimento e no metal de solda da raiz nas peças de testes PT-01 e PT-02 após TTAT. O ataque foi realizado com solução de Nital $2 \%$ e a observação realizada por microscopia óptica. 

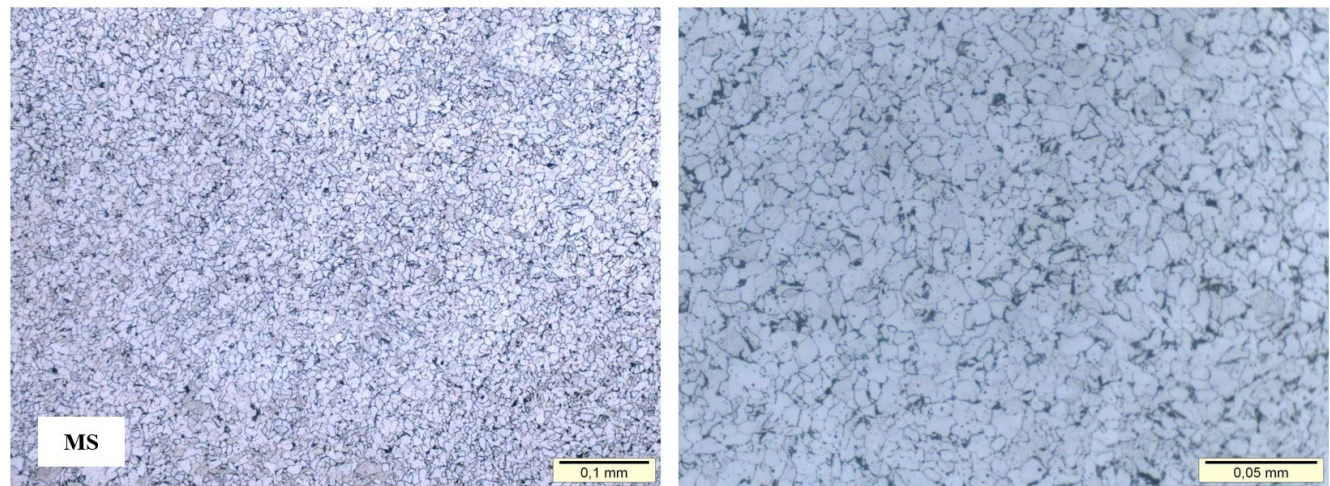

Figura 7. Microestrutura - PT-01 - Metal de solda (MS) - Raiz. Textura recristalizada de grão finos de ferrita com presença de carbonetos.
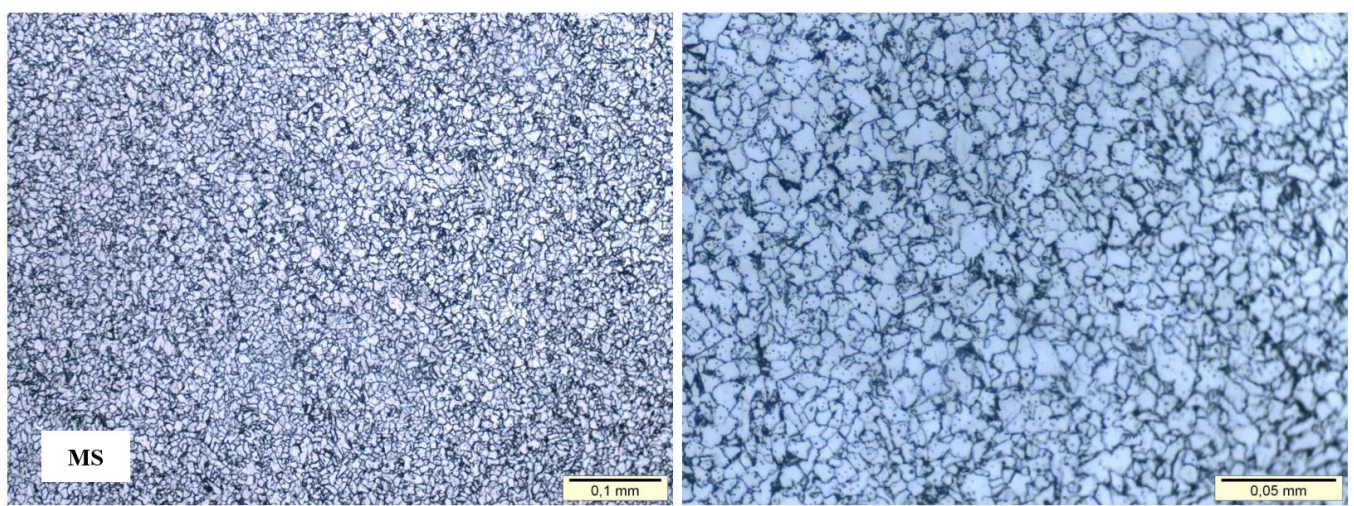

Figura 8. Microestrutura - PT-02 - Metal de solda (MS) - Raiz. Textura recristalizada de grão finos de ferrita com presença de carbonetos.
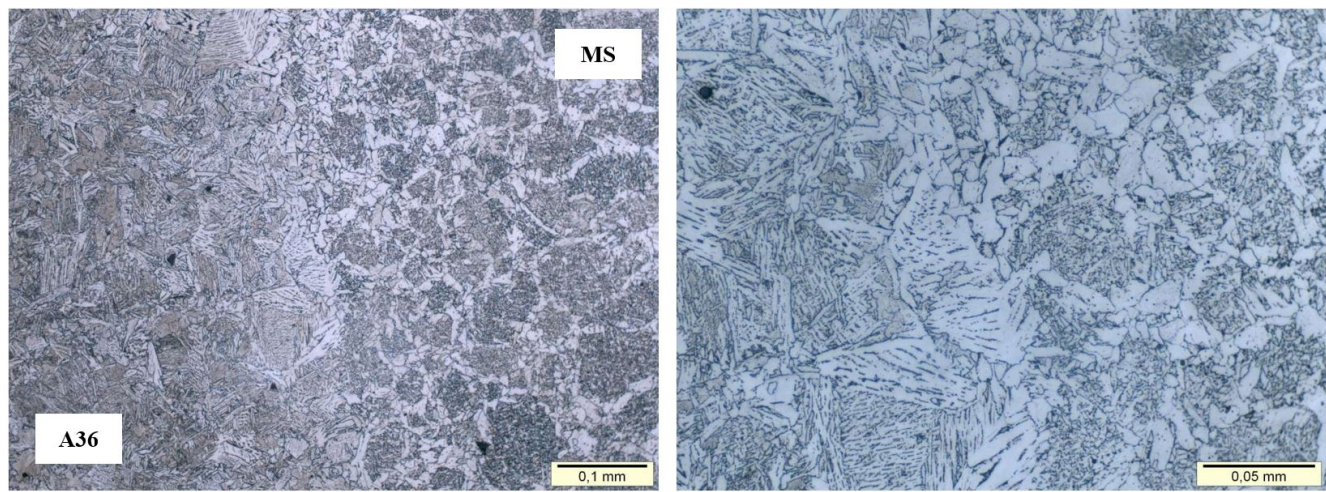

Figura 9. Microestrutura - PT-01 - ZAC (MB × MS) Região do meio-raio. Possivelmente martensita revenida, bainita, ferrita acicular e redes de ferrita primária.
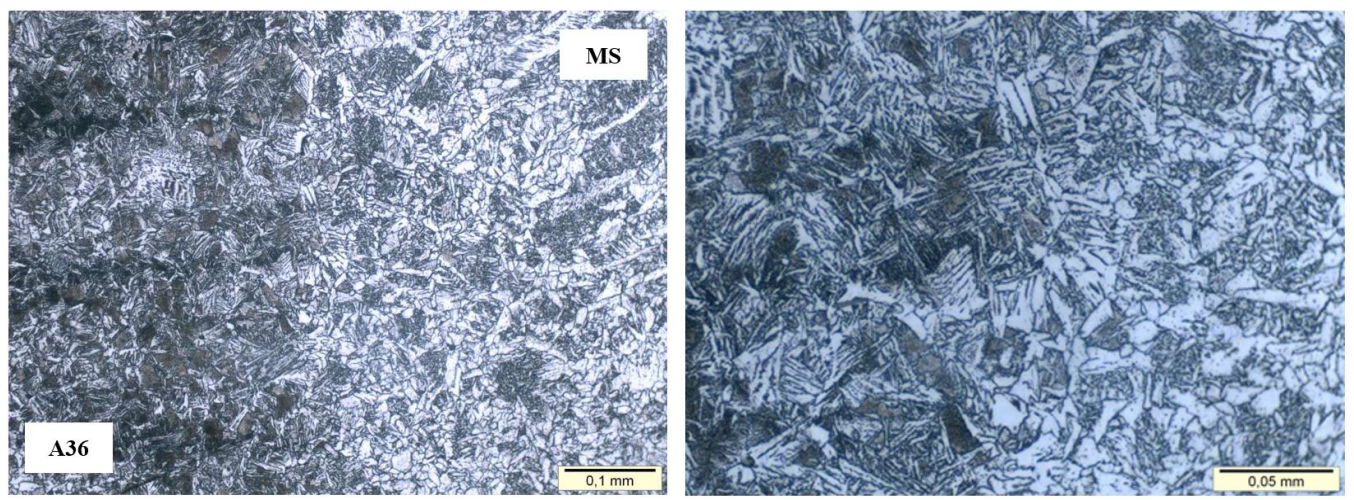

Figura 10. Microestrutura - PT-02 - ZAC (MB $\times$ MS) Região do meio-raio. Possivelmente martensita revenida, bainita, ferrita acicular e redes de ferrita primária. 

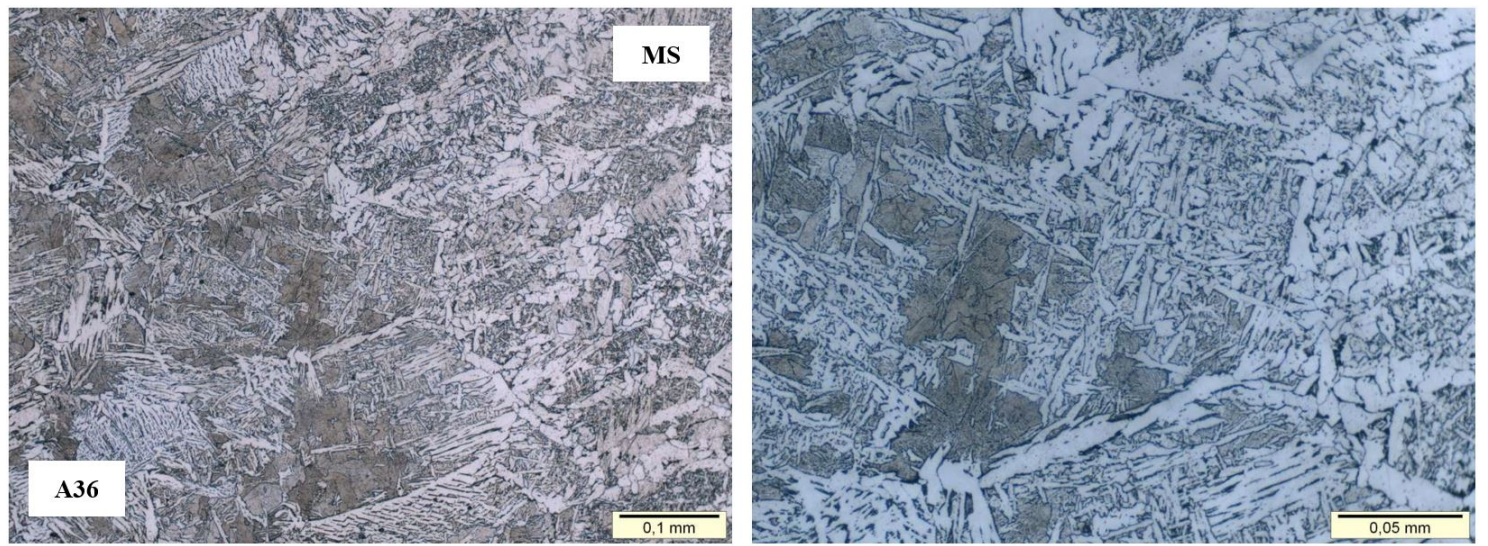

Figura 11. Microestrutura - PT-01 - ZAC (MB × MS) Região do reforço. Martensita revenida, possivelmente bainita, ferrita acicular e redes de ferrita primária.
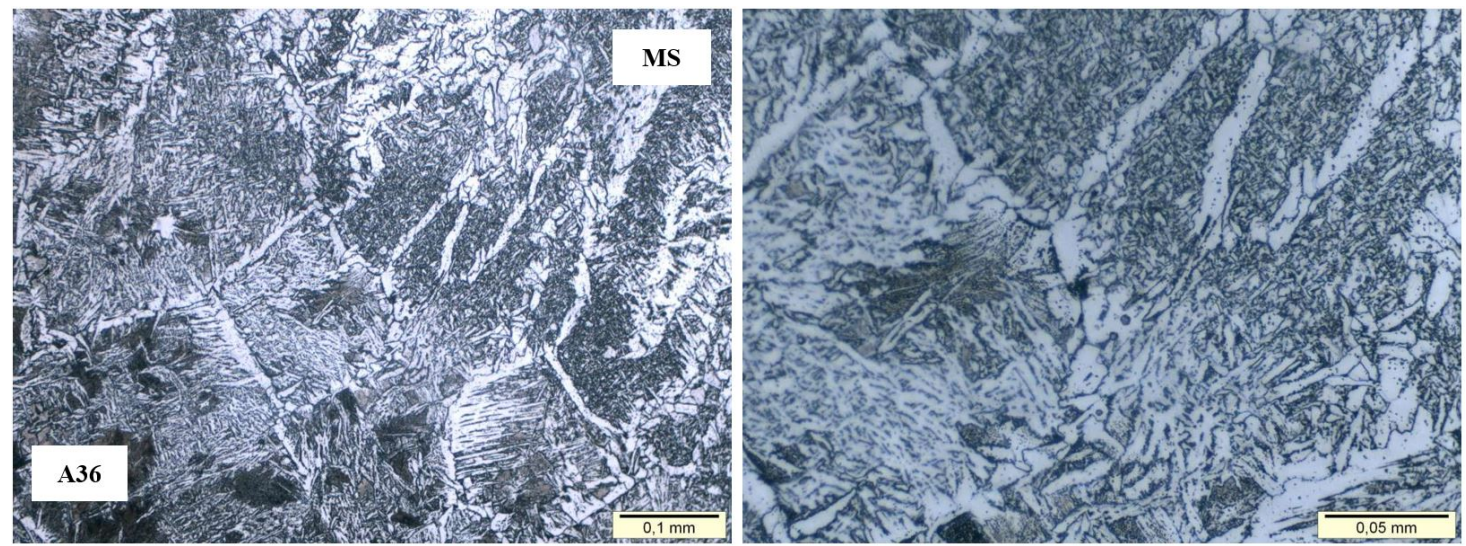

Figura 12. Microestrutura - PT-02 - ZAC (Linha de Fusão - MB $\times$ MS) Região do reforço. Matensita revenida, possivelmente bainita, ferrita acicular e redes de ferrita primária.

A observação das microestruturas nas regiões das ZAC's corrobora com o previsto pelos diagramas mostrados na Figura 6. Pela análise das micrografias das ZAC's nota-se que a presença significativa de microestruturas aciculares (ferríticas e martensíticas) que se constituem em barreiras para a propagação das trincas, o que acarreta em aumento da tenacidade. É possível que tais microestruturas aciculares tenham contribuído para a boa tenacidade encontrada no ensaio de impacto Charpy. No metal de solda, próximo a linha de fusão nota-se a presença de ferrita primária, que possui efeito deletério quanto a tenacidade, porém também há a presença de outras morfologias de ferrita como ferrita secundária de segunda fase alinhada e não alinhada e também de ferrita acicular, sendo esta ultima benéfica no sentido de melhorar a tenacidade. No centro do metal de solda, na região da raiz, observa-se a presença de grãos finos de ferrita recristalizada. Esta região é fortemente influenciada pelo efeito de revenimento da soldagem multi-passe. Com relação ao reforço da solda, nota-se a presença de microestruturas mais grosseiras e também um maior volume de ferrita primária. Por outro lado, nota-se também a presença de ferrita acicular.

De um modo geral, apesar do processo com arco duplo apresentar maiores valores de aporte de calor e maior tempo de resfriamento $\mathrm{t} 5 / 8$, as microestruturas produzidas foram bastante semelhantes àquelas formadas no processo com arco simples.

\section{Conclusões}

Tendo em vista os resultados obtidos pode-se concluir que:

a) O processo arco submerso (SAW) com arco duplo (Tandem-Arc) pode ser empregado na soldagem de chapas de aço carbono ASTM A36 quando há requisitos de impacto.

b) Com base nos resultados obtidos é possível, de acordo com o código ASME IX, qualificar um procedimento de soldagem para aços carbono P1Gr.1 pelo processo arco submerso com arco duplo (Tandem-Arc).

c) Os valores de dureza medidos nas ZAC's estão coerentes com os valores previstos pelo modelo de Yurioka.

d) Os valores de tenacidade obtidos no ensaio Charpy, sugerem que a temperatura de transição dúctil-frágil é inferior a $-20^{\circ} \mathrm{C}$.

e) As microestruturas obtidas na soldagem com arco simples e duplo foram semelhantes. 


\section{Agradecimentos}

Ao Instituto de Pesquisas Energéticas e Nucleares - IPEN, a Faculdade de Tecnologia de São Paulo, a Prensas Schuler Brasil S/A, a ITW Welding Brasil e ao Operador de Soldagem Manoel Heleno da Silva Filho.

\section{Referências}

[1] Paranhos R, Souza AC. Soldagem a arco submerso - coleção soldagem 2000. Rio de Janeiro: FIRJAN/SENAl; 1999.77 p.

[2] American Society for Testing and Materials. A36/A36M: specification for carbon structural steel. West Conshohocken: ASTM; 2014.

[3] American Society of Mechanical Engineers. ASME Section IX: qualification standard for welding and brazing procedures, welders, brazers, and welding and brazing operators - Boiler and pressure vessel code. New York: ASME; 2015.

[4] Deutsches Institut für Normung. DIN EN 10025-2: standard hot rolled products of structural steels - part 2: technical delivery conditions for non-alloy structural steel. Berlin: DIN; 2004.

[5] American Welding Society. A5.17-1997: specification for carbon steel electrodes and fluxes for submerged arc welding. Miami: AWS; 1997

[6] Petróleo Brasileiro SA. N-133: norma soldagem. Rio de Janeiro: Petrobras; 2012.

[7] American Society of Mechanical Engineers. ASME Section VIII Div.1: design and fabrication of pressure vessels - Boiler and pressure vessel code. New York: ASME; 2015.

[8] American Society for Testing Materials. A370-13: standard test methods and definitions for mechanical testing of steel products. West Conshohocken: ASTM; 2013.

[9] The Welding Institute. Mechanical testing: tensile testing - part 2. Cambridge: TWl; 2018 [acesso em 18 maio 2018]. Disponível em: http://www.twi-global.com/technical-knowledge/job-knowledge/mechanical-testing-tensiletesting-part-2-070/

[10] Lancaster JF. Metallurgy of welding. 6th ed. Cambridge: Abington Publishing; 1999. 468 p. http://dx.doi.org/10.1533/9781845694869.

[11] Granjon H. Les bases métallurgiques du soudage. France: Institut de Soudure; 2000. 233 p.

[12] Yurioka N, Okumura M, Kasuya T, Cotton HJU. Prediction of HAZ hardness of transformable steels. Metals Construction. 1987;19(4):217223.

[13] Deutsches Institut für Normung. DIN EN 1011-2: standard welding - recommendation for welding of metallic materials - part 2: arc welding of ferritic steels. Berlin: DIN; 2001.

[14] Akbarnejad S. Investigation on static strenght of welded joints [Master thesis]. Stockholm: Royal Institute of Technology; 2012.

[15] ArcelorMittal USA. Guidelines for fabricating and processing plate steel. Burns Harbor: ArcelorMittal; 2006 [acesso em 18 maio 2018]. Disponível em: https://usa.arcelormittal.com/ /media/Files/A/Arcelormittal-USA-V2/what-we-do/steel-products/plateproducts/fabrication-guide.pdf

[16] Evans GM, Bailey N. Metallurgy of basic weld metal. 1st ed. Cambridge: Abington Publishing; 1997. 432 p. http://dx.doi.org/10.1533/9781845698850.

[17] Dieter GE. Mechanical metallurgy. McGraw-Hill Book Co; 1988. 751 p

[18] Fujii H, Ichikawa K. Estimation of weld properties by bayesian neural network. Welding in the World. 2001;70(3):335-339. 